\title{
Factor XI Inactivation
}

National Cancer Institute

\section{Source}

National Cancer Institute. Factor XI Inactivation. NCI Thesaurus. Code C131668.

Presence of inactivating antibodies to factor XI in the blood. 